\title{
Structure-activity delineation of quinones related to the biologically active Calothrixin B
}

\author{
Paul H. Bernardo, ${ }^{\text {a }}$ Christina L. L. Chai, ${ }^{\mathrm{a}, *}$ Maurice Le Guen, ${ }^{\mathrm{a}}$ \\ Geoffrey D. Smith ${ }^{\mathrm{b}}$ and Paul Waring ${ }^{\mathrm{a}}$ \\ ${ }^{a}$ Department of Chemistry, Australian National University, Canberra, ACT 0200, Australia \\ ${ }^{\mathrm{b}}$ School of Biochemistry and Molecular Biology, Australian National University, Canberra, ACT 0200, Australia
}

Received 25 May 2006; revised 14 September 2006; accepted 29 September 2006

Available online 4 October 2006

\begin{abstract}
Quinones such as Calothrixins A and B display a range of biological properties. As part of our ongoing studies to elucidate the mechanism of action of the Calothrixins, several related quinones were synthesized and tested for biological activity. The results of the structure-activity relationship (SAR) studies are reported here.

(C) 2006 Elsevier Ltd. All rights reserved.
\end{abstract}

Quinones are a remarkable class of compounds commonly found in nature. Many cofactors of enzymes such as menadione (1) and ubiquinone (2) play an integral role in cellular respiration and/or photosynthesis in both prokaryotic and eukaryotic organisms. In addition, a large number of biologically active secondary metabolite quinones have been isolated from various sources such as plants, fungi, and marine organisms. The functions of these unique secondary metabolites are less clearly delineated, but these compounds often display selective toxicity toward foreign organisms. There are many naturally occurring quinones which possess anti-oxidant, anti-inflammatory, and anti-tumor activities. ${ }^{1}$ The modern arsenal of chemotherapeutic quinones includes doxorubicin (3) and mitomycin C (4). ${ }^{2,3}$

The biological mode of action of the quinones is dependent on their structure, and they can act as covalent modifiers of biomolecules, DNA intercalators, and/or generators of reactive oxygen species through redox-cycling. ${ }^{4,5}$ The more structurally complex quinones are believed to be polymodal in their action. For instance, the anthracycline quinones such as doxorubicin can intercalate with DNA, undergo reductive activation to form

\footnotetext{
Keywords: SAR.

* Corresponding author at present address: Institute of Chemical and Engineering Sciences, 1 Pesek Road, Jurong Island, Singapore 627833, Singapore. Tel.: +65 67963902; fax: +65 63166184; e-mail: Christina_Chai@ices.a-star.edu.sg
}

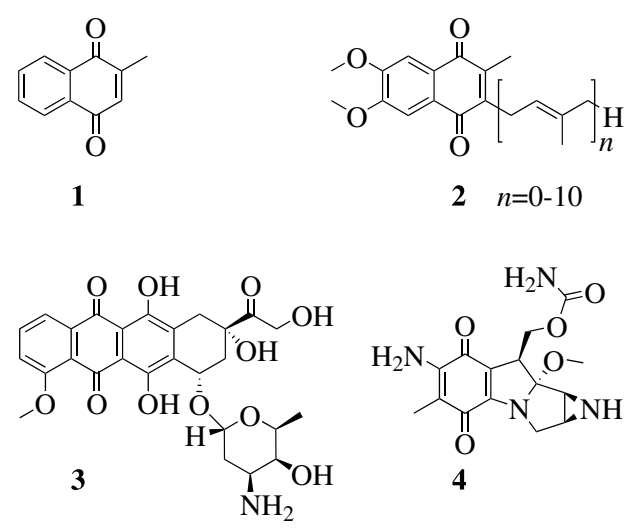

reactive methide intermediates, covalently modify biomolecules, induce DNA scission, and inhibit RNA synthesis. ${ }^{6,7}$

Our own interest in quinones is centered on the elucidation of the biological modes of action of carbazolediones such as the Calothrixins A (5) and B (6). Both compounds were isolated from the Calothrix cyanobacteria and possess a novel indolo[3,2-j]phenanthridine pentacyclic ring system. When tested against a chloroquine-resistant strain of Plasmodium falciparum and human HeLa cervical cancer cells, both compounds inhibited cell growth in a dose-dependent manner within the nanomolar range. ${ }^{8}$ These compounds have also been shown to inhibit bacterial RNA polymerase. ${ }^{9}$ 

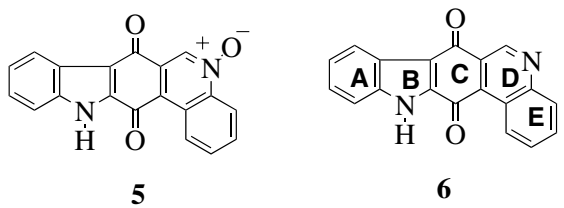

In an earlier study, we reported that there was no direct correlation between the antiproliferative activity of the Calothrixins and related carbazolediones on HeLa cells, and the reduction potentials of these quinones. ${ }^{10}$ As part of our ongoing studies to elucidate the structural requirements for the biological activity of these compounds, several simple quinone analogues of Calothrixin B were synthesized. These quinones were chosen to probe the importance of the rings A-E of Calothrixin B. In addition, the selectivity of these compounds was also determined by measuring the antiproliferative activity of the quinones against three different cell lines. The cell lines chosen were the human HeLa cervical cancer cells, the murine P388 macrophage cancer cells, and the simian CV-1 non-cancerous cells. We employed the MTT assay which measures cell viability based on the inclusion and metabolism of 3-(4,5-dimethylthiazol-2-yl)-2,5-diphenyl-2 $H$-tetrazolium bromide to the dark blue formazan dye by living cells. ${ }^{11}$ The percentage of living cells was determined by the concentration of formazan dye as measured at $590 \mathrm{~nm}$ by an ELIZA plate reader, and a dose-response curve was generated from the data. The $\mathrm{EC}_{50}$ values were then extrapolated from the dose-response curve.
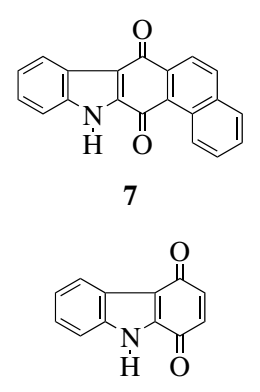

9

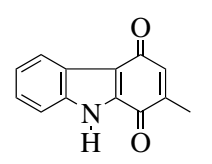

11
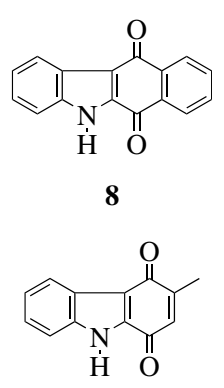

10

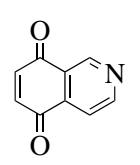

12
Calothrixin B (6) was synthesized using the method of Bernardo et al. as previously reported. ${ }^{2,13}$ The general strategy for the synthesis of carbazolediones shown in Scheme 1 is based on the methodology developed by Yogo et al. ${ }^{14}$ The first step involves the Michael addition of aniline to the respective quinone substrates followed by aerial oxidation to give the corresponding anilinoquinones.

The addition of aniline to 1,4-benzoquinone (13) yielded 2 -anilino-1,4-benzoquinone (15) in $67 \%$ yield. The addition of aniline to 2-methyl-1,4-benzoquinone (14) gave a mixture of 2-anilino-5-methyl-1,4-benzoquinone (16) and 2-anilino-6-methyl-1,4-benzoquinone (17) in 2:1 ratio with an overall yield of $87 \%$. The melting points and ${ }^{1} \mathrm{H}$ NMR spectra of the anilinomethylbenzoquinones thus obtained were in excellent agreement with the literature values. ${ }^{14}$ In contrast, our studies showed that the regioselectivity of aniline addition to phenanthrene-7,10-dione (19) was 5:1, in favor of 9-anilinophenanthrene-7,10-dione (21), with an overall yield of $69 \%$. The minor regioisomer was unambiguously determined by single-crystal X-ray diffraction studies, indirectly establishing the regiochemistry of the major isomer.

The second step in the general strategy utilizes a palladium(II)-mediated cyclization reaction to convert the anilinoquinones to their respective carbazolediones (7-11).

Isoquinoline-5,8-dione (12) was prepared from isoquinolin-5-ol following the procedure of Barret and Daudon. ${ }^{15}$

Several assays have been reported in the literature for measuring the antiproliferative activity of quinones. In this study, the antiproliferative activities of the chosen quinones were measured using the colorimetric MTT assay. The MTT assay was chosen due to its relative ease of handling as well as the reproducibility of results. The results are shown in Table 1 .

Calothrixin B (6) displayed the highest activity against $\mathrm{HeLa}$ cells with an $\mathrm{EC}_{50}$ of $0.25 \mu \mathrm{M}$. Indolophenanthrenedione (7) was the second most active compound against HeLa cells, followed by the benzocarbazoledione (8). By comparison, 2-methylcarbazole $(\mathbf{1 1})^{14}$ displayed only moderate activity, whereas murrayaquinone $\mathrm{A}(\mathbf{1 0})$ and isoquinolinedione (12) showed weak activity with $\mathrm{EC}_{50}$ values of 13 and $12 \mu \mathrm{M}$, respectively. The carbazoledione (9) ${ }^{16,17}$ was inactive against HeLa cells as well as the other two cell lines.

From these studies with the HeLa cell lines, it appears that rings A-D are necessary for good activity (comparison of quinones 6-8 with 9-12). Ellipticine quinone (22) was reported to have an $\mathrm{EC}_{50}$ value of $0.15 \mu \mathrm{M}$ against the HeLa cell lines. ${ }^{10}$ The observed $\mathrm{EC}_{50}$ value for isoquinolinedione (12) is 80 -fold less than this, supporting the importance of rings $\mathrm{A}-\mathrm{C}$ in the biological activity against HeLa cell lines. Similarly, the absence of the nitrogen atom in the D-ring (indolophenanthrene 7 versus Calothrixin 6) resulted in a drop in the potency observed. This is consistent with the previously reported observations with benzocarbazoledione and ellipticine quinone (22). ${ }^{10}$ These trends, however, were not observed with the P388 and CV-1 cell lines. It is interesting to note the 2-fold difference in the $\mathrm{EC}_{50}$ values of the two regioisomers, murrayaquinone A (10) and 2-methylcarbazoledione (11). Although it would be tempting to speculate that this difference may have arisen from the different Michael acceptor properties of the quinones, the lack of activity of carbazoledione (9) suggests that this rationale may be too simplistic. 

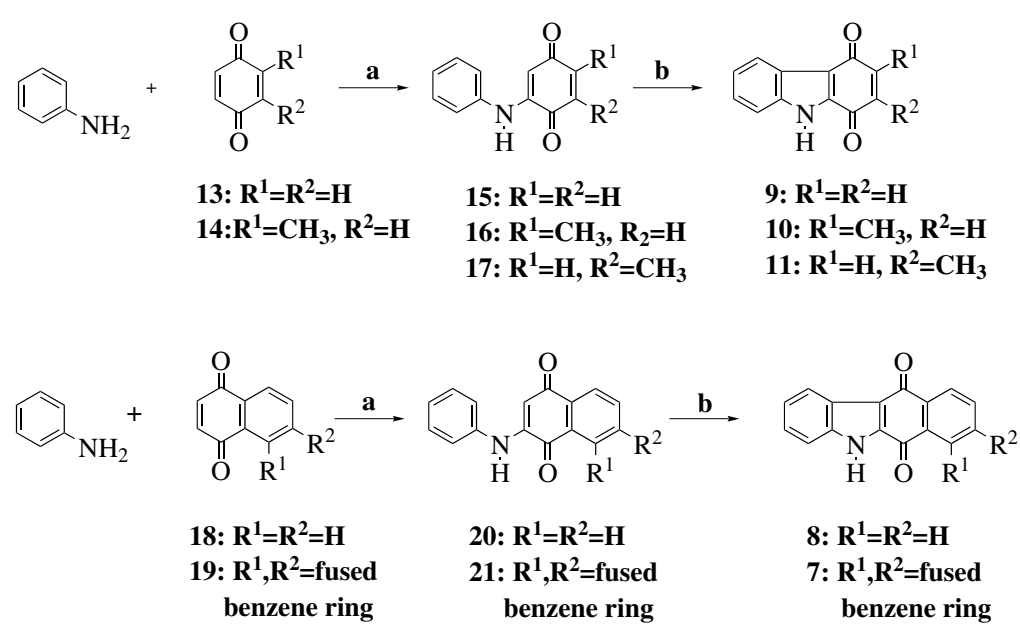

Scheme 1. Reagents and conditions: (a) $\mathrm{H}_{2} \mathrm{O}-\mathrm{AcOH}$, for 2-methylbenzoquinone as substrate, reaction was carried out at rt; for benzoquinone as substrate, reaction was carried out at $0{ }^{\circ} \mathrm{C}$; for naphthoquinone as substrate, reaction was carried out at reflux temperature; yields were between 49 and $62 \%$; (b) 1 equiv $\mathrm{Pd}(\mathrm{OAc})_{2}$, glacial $\mathrm{AcOH}$, reflux; yields were $18-62 \%$.

Table 1. Cytotoxicity of the test compounds towards three cell lines

\begin{tabular}{llll}
\hline Compound & $\mathrm{EC}_{50}(\mu \mathrm{M}) \mathrm{HeLa}$ cells & $\mathrm{EC}_{50}(\mu \mathrm{M}) \mathrm{P} 388$ cells & $\mathrm{EC}_{50}(\mu \mathrm{M}) \mathrm{CV}-1$ cells \\
\hline Calothrixin B (6) & $0.25 \pm 0.05$ & $9 \pm 2$ & $2.4 \pm 0.7$ \\
Indolophenanthrene-7,13-dione (7) & $1.5 \pm 0.3$ & $>50$ & $>50$ \\
Benzocarbazoledione (8) & $1.8 \pm 0.1^{\mathrm{a}}$ & $>50$ & $>50$ \\
Carbazole-1,4-dione (9) & $>50$ & $>50$ & $>50$ \\
Murrayaquinone A (10) & $13 \pm 1$ & $2.3 \pm 0.3$ & $10 \pm 2$ \\
2-Methylcarbazoledione (11) & $7 \pm 1$ & $1.0 \pm 0.1$ & $1.7 \pm 0.4$ \\
Isoquinoline-5,8-dione (12) & $12 \pm 1$ & $9 \pm 2$ & $>50$ \\
\hline
\end{tabular}

${ }^{\mathrm{a}}$ In a previous study with HeLa cells, the $\mathrm{EC}_{50}$ for benzocarbazoledione was found to be $0.43 \pm 0.1 \mu \mathrm{M} .{ }^{10}$

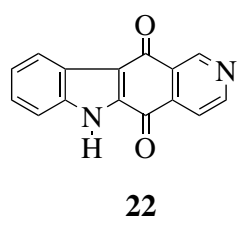

With respect to the P388 cell line, 2-methylcarbazoledione (11) and murrayaquinone A (10) were found to have good activity. Isoquinolinedione (12) was less potent than both murrayaquinone $\mathrm{A}$ and 2-methylcarbazoledione. Calothrixin B (6) and the isoquinolinedione (12) displayed equipotent and moderate antiproliferative activity $\left(\mathrm{EC}_{50}=9 \mu \mathrm{M}\right)$. The other compounds tested had no effect on the proliferation of P388 cells.

2-Methylcarbazoledione (11) and Calothrixin B (6) showed similar activity against non-cancerous CV-1 cells. Murrayaquinone A (10) showed only moderate activity. In contrast, the other quinones tested were not active against this cell line.

The selectivity of the compounds is determined by comparison of the $\mathrm{EC}_{50}$ values obtained for the three cell lines. A compound with good selectivity displays potent antiproliferative activity against the cancer cell lines and only moderate or poor antiproliferative activity against the $\mathrm{CV}-1$ cells.

Calothrixin B (6) displayed activity against all three cell lines. The $\mathrm{EC}_{50}$ observed was $0.25 \mu \mathrm{M}$ against
HeLa cells, but only $2.4 \mu \mathrm{M}$ against CV-1 and $9 \mu \mathrm{M}$ against P388 cells. This shows that Calothrixin B is almost 10 times more active against $\mathrm{HeLa}$ than against CV-1 normal cells, and 38 times more active against HeLa than P388 cancer cells. The large difference in the $\mathrm{EC}_{50}$ values observed shows that Calothrixin $\mathrm{B}$ can be used selectively against $\mathrm{HeLa}$ at low concentrations.

Indolophenanthrenedione (7) and benzocarbazoledione (8) display the greatest selectivity, with $\mathrm{EC}_{50}$ values of $1.5 \mu \mathrm{M}$ and $1.8 \mu \mathrm{M}$, respectively, against HeLa cancer cells, and no measurable activity against P388 and CV1 cells. The isoquinolinedione (12) displayed selective activity against both cancer cell lines with no activity against the CV-1 cells. Murrayaquinone A (10), the activity of which has been reported for other cell lines, ${ }^{18}$ showed a 4-fold difference in activity against $\mathrm{P} 388$ versus the other cell lines, but displayed poor specificity between CV-1 $\left(\mathrm{EC}_{50}=10 \mu \mathrm{M}\right)$ and $\mathrm{HeLa}$ cells $\left(\mathrm{EC}_{50}=13 \mu \mathrm{M}\right)$. 2-Methylcarbazoledione (11) likewise displayed poor selectivity between P388 and CV-1 cell lines.

This study shows that simpler analogues of Calothrixin B display varying degrees of potency against different cell lines. Of the compounds tested, indolophenanthrenedione (7) and benzocarbazoledione (8) are the most selective in their activity against HeLa cells. The differences in $\mathrm{EC}_{50}$ values obtained for Calothrixin $\mathrm{B}$ against 
the different cell lines also highlight its specific utility against HeLa cells. With respect to P388 cells, only murrayaquinone A shows desirable selectivity. Further studies are needed in order to further our understanding of the structural requirement for greater selective bioactivity.

\section{References and notes}

1. Thomson, R. H. In Naturally Occurring Quinones; Thomson, R. H., Ed.; Academic Press Inc.: London, 1971; p 1.

2. Tomasz, M. Chem. Biol. 1995, 2, 575.

3. Powis, G. Free Radical Biol. Med. 1989, 6, 63.

4. Bolton, J. L.; Trush, M. A.; Penning, T. M.; Dryhurst, G.; Monks, T. J. Chem. Res. Toxicol. 2000, 13, 135.

5. O'Brien, P. J. Chem. Biol. Interact. 1991, 80, 1.

6. Pigram, W. J.; Fuller, W.; Hamilton, L. D. Nature 1972, 235, 17.

7. Berlin, V.; Haseltine, W. A. J. Biol. Chem. 1981, 256, 4747.
8. Rickards, R. W.; Rothschild, J. M.; Willis, A. C.; de Chazal, N. M.; Kirk, J.; Kirk, K.; Saliba, K. J.; Smith, G. D. Tetrahedron 1999, 55, 13513.

9. Doan, N. T.; Stewart, P. R.; Smith, G. D. FEMS Microbiol. Lett. 2001, 196, 135.

10. Bernardo, P. H.; Chai, C. L. L.; Heath, G. A.; Mahon, P. J.; Smith, G. D.; Waring, P.; Wilkes, B. A. J. Med. Chem. 2004, 47, 4958.

11. Mosmann, T. J. Immunol. Methods 1983, 65, 55.

12. Bernardo, P. H.; Chai, C. L. L.; Elix, J. A. Tetrahedron Lett. 2002, 43, 2939.

13. Bernardo, P. H.; Chai, C. L. L. J. Org. Chem. 2003, 68, 8906.

14. Yogo, M.; Ito, C.; Furukawa, H. Chem. Pharm. Bull. 1991, 39, 328.

15. Barret, R.; Daudon, M. Tetrahedron Lett. 1990, 31, 4871.

16. Martin, R.; Moody, C. J. J. Chem. Soc., Perkin Trans. 1 1988, 235.

17. Teuber, H. J.; Staiger, G. Chem. Ber. 1954, 87, 1251.

18. Itoigawa, M.; Kashiwada, Y.; Ito, C.; Furukawa, H.; Tachibana, Y.; Bastow, K. F.; Lee, K.-H. J. Nat. Prod. 2000, 63, 893 . 